\title{
QUESTÕES DE AÇÃO LETRADA NO PROCESSO DE ESCRITA DO PRÓLOGO DA CARTA AOS HEBREUS
}

\author{
ISSUES OF LITERATE ACTION IN THE PROCESS OF \\ WRITING OF THE PROLOGUE OF THE LETTER TO THE \\ HEBREWS
}

\author{
Edivaldo Ferreira de Arruda* \\ Benedito Gomes Bezerra**
}

Resumo: A Carta aos Hebreus é um texto bíblico de fonte híbrida - hebraica e grega - interessante para se observar os recursos de letramento usados pelo autor sob a perspectiva da intertextualidade. O objetivo deste estudo é analisar marcas de ação letrada no prólogo $\mathrm{Hb}$ 1.1-4, tomado como corpus para análise de tópicos linguísticodiscursivos que confluem do ontem para o hoje, em práticas sociais recorrentes. À vista dessas questões, o estudo se baseia em aportes teóricos encontrados em Bazerman (2015a; 2015b), à luz da "retórica da ação letrada", e em Street (2014) na visão de letramento que sublinha as práticas sociais. A partir de uma análise qualitativa, refletimos sobre as estratégias de ação letrada no prólogo, centrando-nos em pesquisas pautadas no exame de corpora bibliográficos. Esse procedimento revelará que a ação letrada não depende da condição intelectual privilegiada de parte dos membros de grupo social, mas envolve participantes responsáveis em atividades cotidianas.

Palavras-chave: Carta aos Hebreus; Discurso; Letramento.

AвstRACT: The Letter to the Hebrews is a biblical text with a hybrid font - Hebrew and
Greek - interesting to observe the literacy resources used by the author under the
perspective of intertextuality. The aim of this study is to point out marks of literate
action in the prologue $\mathrm{Hb}$ 1.1-4, taken as a corpus for the analysis of linguistic-
discursive topics that converge from yesterday to today, in recurring social practices.

\footnotetext{
"Doutorando em Ciências da Linguagem e Mestre em Teologia pela Universidade Católica de Pernambuco (UNICAP). Licenciatura em Física pela Universidade Federal Rural de Pernambuco (UFRPE). Teologia nos Seminários STBNB e STPN. Orcid: https://orcid.org/0000-0003-4121-7380.E-mail: edivaldofa@gmail.com.

"* Doutor em Letras/Linguística pela Universidade Federal de Pernambuco (UFPE). Docente do Programa de Pós-Graduação em Ciências da Linguagem da Universidade Católica de Pernambuco (PPGCL/UNICAP) e do Programa de Mestrado Profissional em Letras da Universidade de Pernambuco (PROFLETRAS/UPE). Orcid: https://orcid.org/oooo0002-7382-0937. E-mail: beneditobezerra@gmail.com.
} 
In view of these issues, the study is based on the theoretical contributions found in Bazerman (2015a; 2015b) in the light of the "rhetoric of literate action" and in Street (2014) through the vision of literacy that underlines the social practice. Based upon a qualitative research, we reflect on the strategies of literate action in the prologue, focusing on research based on bibliographic corpus analysis. This procedure will reveal that literate action is not restricted to the privileged intellectual condition of members of a social group, but involves responsible participants in everyday activities.

KeYwords: The Letter to the Hebrews; Discourse; Literacy.

\section{INTRODUÇão}

Nos dias que antecederam a eclosão do movimento de Jesus, havia, no judaísmo da época, uma expectativa pela chegada do Messias. Nesse período, constata-se a formação de grupos sociais e religiosos - ora norteados pela leitura dos escritos precedentes, ora nutridos pelos discursos de profetas autorizados pelo Deus da Antiga Aliança - alinhados sobretudo pelo interesse de preservar a informação religiosa advinda da tradição. Nessa cadeia de interação, os discursos eram comumente elaborados para uma leitura responsiva diante da comunidade da fé.

Ademais, no decurso da trajetória que envolve a tradição judaica não havia somente a necessidade de preservar seus valores, mas também a necessidade de sua interpretação (por exemplo: em geral, nas sinagogas, as reuniões visavam refletir e aprofundar conhecimentos sobre os textos do Antigo Testamento (AT), ${ }^{1}$ como se observa no capítulo 7 do livro de Atos, onde Estevão faz uma explanação em forma de sermão). ${ }^{2}$ Nesses casos, eram usados textos dos salmos, dos provérbios e de outros escritos tidos como sagrados. A partir daí, surgem várias tradições de leitura, de interpretação dos escritos do judaísmo, ${ }^{3}$ tais como: Midrash, Mishnah, Gemara, Halacha, Talmud etc.

Em que pesem as marcas dessas tradições na fé judaico-cristãa, ${ }^{4}$ devemos observar o quanto a condição de letramento habilitava uma leitura fluida para as audiências imediatas dos textos a que foram destinados. A condição de letramento diz respeito à capacidade do grupo de manusear os textos do AT no entorno das práticas cristãs reais durante o período primitivo.

\footnotetext{
${ }^{1}$ Ou Bíblia Hebraica, ou, ainda, Primeiro Testamento.

${ }^{2}$ Isso ocorria em muitas reuniões, cf. Atos 13.15: "Depois da leitura da Lei e dos Profetas, os chefes da sinagoga lhes mandaram dizer: "Irmãos, se vocês têm uma mensagem de encorajamento para o povo, falem".

${ }^{3}$ Por exemplo, a Mishnah significa "repetição" e aplicava-se às práticas da leitura oral visando a transmitir adequadamente o conhecimento da tradição. Não é nosso objetivo discutir os pormenores dessas correntes.

${ }^{4} \mathrm{~A}$ ideia de uma tradição judaico-cristã reflete a cnsolidação de uma fronteira entre um judaísmo tradicional anterior a Cristo e um judaísmo novo moldado por ações, digamos, letradas a partir dos textos do AT.
} 
Walton e Sandy (2013, p. 83) apontam que, no período helênico, aprender era privilégio de menos de 10 por cento da população que tinha acesso à alfabetização, "a ponto de as pessoas não saberem ler obras literárias nem escrever literatura". ${ }^{5}$ Nesse contexto, em que os autores descrevem a oralidade como "intuitiva”, a textualidade escrita não fazia parte da realidade da maioria das pessoas. De fato, a Antiguidade conhece mais ouvintes do que leitores do texto escrito.

Nesse sentido, é preciso entender em que medida os textos cristãos foram escritos para usos litúrgicos durante uma leitura pública se não fossem destinados a audiências letradas nos elementos da retórica grega clássica. Nesse período, afirma Siegert (2001, p. 427), os escritores eram treinados para lidar com a comunicação de massa. Hebreus se caracteriza como um texto da "segunda geração" (final do século I) dos escritos cristãos, portanto, mais conforme e aculturado ao helenismo.

De acordo com Jaeger (2013, p. 476) "foi a paideía ${ }^{6}$ grega que lançou as bases da ardente e secular disputa travada entre o espírito grego e a religião cristã (cada um dos quais se esforçava por dominar e assimilar o outro) bem como da sua síntese final”. Fato é que, com o início das práticas cristãs no final do século I, novas estratégias se somam às práticas de leitura. A experiência cristã se vê diante de formas de comunicação híbridas, tendo que deslocar sua concepção etnocêntrica judaica para uma perspectiva inclusiva centrada no ideal de transmitir valores a partir da interação social com outros povos.

Diante disso, o objeto deste estudo é o prólogo da Carta aos Hebreus $(\mathrm{CH})$, frequentemente tomada como um sermão ou um tipo de homilia em forma de conversa (SIEGERT, 2001). De acordo com Lane (1991, p. lxxvi), os recursos linguísticos gregos empregados dão conta de que a construção do enunciado "advêm da necessidade de prestar assistência oral aos ouvintes", de modo que "o texto escrito não foi criado para os olhos, mas para os ouvidos, para emitir uma sensação de estrutura e desenvolvimento".

Hoje, os textos do Novo Testamento (NT) orientam as práticas cristãs, e as comunidades de fé se valem deles para desenvolver complexos eventos de letramento bem como atividades de oralidade. Diante do exposto, objetivamos analisar as marcas de ação letrada a partir do propósito comunicativo do prólogo de Hebreus ( $\mathrm{PH})$.

Por se tratar de um sermão cristão primitivo materializado em texto escrito, no primeiro tópico, destacaremos alguns princípios teóricos que servirão de orientação para o estudo. No segundo tópico, observaremos as dinâmicas das falas explícitas e implícitas na escrita. No terceiro, verificaremos como as falas sustentam os atos subsequentes no texto escrito. Enfim, na etapa final, faremos uma análise da ação letrada nesse macrodiscurso do PH.

\footnotetext{
${ }^{5}$ Todas as traduções de citações de obras em língua estrangeira são de nossa responsabilidade, a não ser que haja indicação em contrário.

${ }^{6}$ Paideia ( $\left.\pi \alpha \mathrm{\iota} \delta \varepsilon i ́ \alpha\right)$ é um termo grego usado para expressar a noção de educação na sociedade grega clássica.
} 


\section{AÇÃo LETRADA: CONSIDERAÇõES SOBRE GÊNERO E LETRAMENTO}

Nesta etapa, colocaremos em questão duas noções relacionadas com as interações sociais imanentes no enunciado concreto: gênero e letramento. Essa escolha não é por acaso, haja vista que o objeto desse estudo se encontra em formato textual destinado a uma audiência cristã específica do século I. De acordo com Vanhoozer (2018, p. 89), o texto bíblico se pauta em valores objetivos, todavia "o perigo da interpretação inábil, iletrada, é que, ao se equivocar sobre o gênero do livro, arriscamos errar não só um único versículo, mas todos os outros", uma vez que "a interpretação literal exige conhecimento literário e sensibilidade - em uma palavra, letramento".

Com respeito à noção de gênero, aqui destacamos a perspectiva dos Estudos Retóricos de Gênero (MILLER, 2012; BAZERMAN, 2015a; 2015b). Miller (2012, p. 39) aborda os gêneros a partir dos reflexos históricos das atividades recorrentes e socialmente organizadas que adquirem o "significado da situação e do contexto social em que essa situação surgiu". Para a pesquisadora, os gêneros "ajudam a construir a substância de nossa vida cultural [...], servem de chave para entender como participar das ações de uma comunidade" (p. 41).

Bazerman (2006, p. 23), por sua vez, acrescenta que os gêneros não se restringem a formas, mas envolvem o contexto sócio-histórico e o sujeito cognitivo, mais precisamente os "gêneros são formas de vida, modos de ser. São frames para a ação social. São ambientes para a aprendizagem. São os lugares onde o sentido é construído. Os gêneros moldam os pensamentos que formamos e as comunicações através das quais interagimos".

Nesses lugares, o sujeito constrói enunciados novos que designam um ato responsável. Bakhtin (2012, p. 42) lembra que um ato responsável se situa em dois mundos diferentes onde há "uma separação de princípio entre o conteúdo-sentido de um determinado ato-atividade e a realidade histórica de seu existir, sua vivência realmente irrepetível". É justamente nesse ínterim que (re)aparecem as modalizações de discursos imanentes nos gêneros. Medviédev (2016, p. 206) afirma que "um novo gênero constitui-se a partir dos gêneros existentes; em cada um dos gêneros acontecem reagrupamentos dos elementos previamente dados”.

Por outro lado, é imprescindível notar com Bazerman (2015a, p. 48) "que o gênero é uma categoria psicossocial de reconhecimento e não algo fixado na forma do texto". Isso não quer dizer que devamos dissociar gênero textual de discursivo. Bezerra (2017) sumariza essa questão nos seguintes termos: não existem "gêneros do discurso" e "gêneros textuais" - trata-se de duas terminologias aplicadas a um único objeto. De mais a mais, um sermão tanto pode ser observado pela sua natureza genérica discursiva como pela sua manifestação textual. Em ambos os casos, o que está em alto relevo é o modo relativamente estável de apresentação do objeto de sentido, conforme estabelece o propósito comunicativo de um novo enunciado.

Vimos que as teorias de gêneros de Bakhtin e Bazerman compartilham alguns aspectos comuns os quais abordaremos nesta pesquisa. Na direção mais ampla de comunicação, outras 
questões se distanciam mais de Bakhtin, e avançam em direção a modelos de práticas sociais. Referimo-nos aos letramentos no sentido amplo de prática social em Street (2014).

A comunicação de aspectos (meta)linguísticos armazenados na memória social 7 é uma atribuição do sujeito cognitivo que se situa entre o verbal e o extraverbal dos dizeres. Contudo, uma cultura que se apoia em acontecimentos registrados na escrita exige reconhecer através do artefato textual os dizeres outros. Nesse aspecto, Adam (2019, p. 32-33) sublinha que "a intertextualidade, como memória individual ou coletiva de textos ou fragmentos de textos, é uma parte do interdiscurso, definido como um campo geral dos discursos, organizado em gêneros e próprio de um determinado grupo social". Para Bazerman (2015a), a escrita se enquadra em novas situações e abrange interações que são estabelecidas imaginativamente pelo escritor, para que o leitor tenha condições de reconstruí-las oportunamente. Em suma, os gêneros designam não somente a parte mais estável do enunciado, mas sobretudo preservam determinadas formas de representação de um dizer.

Isto posto, resta-nos falar a respeito das condições de letramento em que os sujeitos cooperam reciprocamente na construção de novos enunciados. Bazerman (2015a, p. 47) lembra que as manifestações genéricas trazem à tona informações relevantes concernentes à condição de letramento dos participantes do discurso, na medida em que se (re)cria conexões com outros eventos ou vínculos com discursos outros, por exemplo: "era uma vez, há muito, muito tempo atrás [...]. Há muito tempo, numa galáxia muito, muito distante [...]. Muitas espécies de compreensões são invocadas posteriormente".

Segundo Street (2014, p. 17), o termo letramento tem relação com as práticas sociais sob ótica transcultural observadas no âmbito da leitura e da escrita; assim, há uma tendência de rejeitar o ponto de vista "dominante do letramento como uma habilidade 'neutra', técnica, e a conceitualização do letramento, ao contrário, como uma prática ideológica, envolvida em relações de poder e incrustrada em significado e práticas culturais específicos".

De mais a mais, sobre práticas ideológicas, ainda sublinhamos em Marcuschi (1997, p. 121) a distinção entre "oralidade e letramento como práticas sociais e [...] fala e escrita como modalidades de uso, recaindo a primeira na observação da realidade sociocomunicativa e, a segunda na análise de fatos linguísticos". Ademais, esclarecemos que "eventos de letramento" e "práticas de letramento" são noções próximas, mas distintas. Segundo Barton (1991, p. 5), eventos de letramento têm a ver com as atividades particulares em que o letramento tem papel regular e repetido, ao passo que as "práticas de letramento são modos culturais gerais de utilização do letramento aos quais as pessoas recorrem num evento letrado".

\footnotetext{
${ }^{7} \mathrm{~A}$ memória social do texto é uma questão que ganhou destaque nos debates sobre a significação das palavras, sobretudo após a virada linguística - um movimento filosófico ocidental que ocorreu no século XX, marcado por transformações no modo de entender a linguagem, especialmente nas obras de Ludwig Wittgenstein, entre elas, Investigações filosóficas na qual ele cunhou a frase: "Os limites de minha linguagem significam os limites de meu mundo". Nesse sentido, a relação "sujeito-objeto" não mais ocupa o lugar privilegiado das significações, ampliam-se os espaços inerentes ao "mundo da vida", conforme Heidegger, "a linguagem é a morada do ser".
} 
Kleiman (2008, p. 18-19) afirma que os recursos autorais ativam a memória de sujeitos letrados que se movem orientados pela condição de "letramento como um conjunto de práticas sociais que usam a escrita, como sistema simbólico e como tecnologia, em contextos específicos, para objetivos específicos". A teoria de letramento, segundo Street (2014), se fundamenta em duas perspectivas: a do modelo autônomo e a do ideológico. O modelo autônomo de letramento traduz-se como perspectiva que se presta a notar a escrita como produto acabado em si mesmo, e que, de acordo com Kleiman (2008, p. 22),

não estaria preso ao contexto de sua produção para ser interpretado; o processo de interpretação estaria determinado pelo funcionamento lógico interno ao texto escrito, não dependendo das (nem refletindo, portanto) reformulações estratégicas que caracterizam a oralidade, pois, nela, em função do interlocutor, mudam-se rumos, improvisa-se, enfim, utilizam-se outros princípios que os regidos pela lógica, a racionalidade, ou consistência interna, que acabam influenciando a forma da mensagem.

Conquanto o modelo autônomo de letramento privilegie as condições lógicas do texto, ele não se atém à compreensão das peculiaridades que envolvem os processos de produção do discurso. Não é proveitoso dialogar com o texto sem entender o mundo estendido do texto, a situação histórica que lhe deu origem, para, no mínimo, construir pontes dialogais amplas.

O modelo ideológico, por outro lado, não se contrapõe ao modelo autônomo, sugere, no entanto, sua ampliação pelo viés contextual. Considera-se neste modelo que

qualquer estudo etnográfico do letramento atestará, por implicação, sua significância para diferenciações que são feitas com base no poder, na autoridade, na classe social, a partir da interpretação desses conceitos pelo pesquisador. [...], faz mais sentido, do ponto de vista da pesquisa acadêmica, admitir e revelar, de início, o sistema ideológico utilizado, pois assim ele pode ser abertamente estudado, contestado e refinado. (STREET apud KLEIMAN, 2008, p. 38).

Em que pesem as acepções sobre o modelo ideológico de letramento, Street (2014, p. 174, 176) nota que a questão contextual ainda é reavaliada por alguns linguistas, pelo fato de considerarem "que o 'contexto' é tão impreciso e frouxo que faria atolar seus estudos precisos e bem atados. [...] A atenção ao contexto social não precisa sufocar ou afogar os aspectos precisos do uso da língua selecionados para o estudo dentro da linguística".

Parece-nos razoável ter em conta o ambiente e a dinâmica dos eventos que perfazem o letramento dentro de "um processo de aprendizagem social e histórica da leitura e da escrita em contextos informais e para usos utilitários", conforme Marcuschi (2010, p. 21). Em vista disso, Street (2014, p. 181) propõe um olhar atento e holístico a respeito do "contexto" voltado 
para o discurso e a etnografia, notando que "[o] argumento de que a escrita não exibe aspectos de 'canais não verbais e paralinguísticos' [...] deriva da visão da produção escrita dentro de uma definição restrita de "contexto social". Kleiman (2008, p. 20) conclui que "o fenômeno do letramento, então, extrapola o mundo da escrita".

Portanto, no processo de escrita em um evento de letramento, o horizonte social não se restringe aos fatos teoricamente estabelecidos, mas alcança as demandas da vida. Os sujeitos cognitivos investem na realização de seus ideais recorrendo a um ou mais eventos de letramento. Neste estudo, por exemplo, observaremos que as práticas sociocristãs sugerem tanto a apreensão de eventos de letramento relacionados com os conteúdos de sentido da fé judaico-cristã como suscita eventos de letramento interculturais, a saber, judaico-helenísticos.

\section{A dinÂMiCa das Falas No PRólogo da CARTa AOS HEBREUS}

Neste tópico, refletiremos sobre o vínculo de cooperação entre as falas explícitas e implícitas na escrita do $\mathrm{PH}$. Antes de tudo, deve-se ressaltar que os escritores do NT usaram recursos retóricos da língua grega ${ }^{8}$ para representar vários aspectos sociais. Janson (2015, p. 100) observa que o fato de o grego ser a língua da administração e do poder no longo período romano assume também um papel importante como primeira língua escrita do cristianismo para formar o NT. Alguns escritores do NT demonstraram habilidades diferenciadas na construção de suas obras. A criatividade autoral tem a ver com a imaginação, que, nos termos de Vanhoozer (2018, p. 141), “é o poder da visão sinótica, a habilidade de compreender totalidades complexas".

A maioria desses escritores de origem judaica gozava de certa inserção no meio social e linguístico diferenciados, pelo que foram envolvidos em práticas de letramento marcadas por compartilhamento intercultural. Embora os textos dos Evangelhos (narrativas da história de Jesus) tenham sido atribuídos a autores com pouca ou nenhuma formação intelectual na cultura helenística, não se pode negar a condição de letramento social arraigada em eventos dispersos do velho mundo em que os autores se articulavam com o fim de transmitir a mensagem cristã às comunidades com as quais interagiram. Desde então, essa mensagem comunica valores em elevado grau de cooperação, conforme a situação social. Esses valores são mediados pela condição de letramento de seus agentes, e não somente pelo desempenho na leitura ou na escrita institucionalizada.

A partir desses pontos de vista, depreendemos que o envolvimento da audiência cristã primitiva caracteriza uma diversidade de ações letradas, a propósito de intentar transmitir a

\footnotetext{
${ }^{8}$ Segundo Wallace (2009, p. 18), o grego predominante no Oriente Antigo era o koinê (comum). Esse foi o idioma falado "de 330 a.C. a 330 d.C., ou seja, das conquistas de Alexandre até a mudança da capital do Império Romano de Roma para Constantinopla”. Wallace (2009) sugere que o grego da Carta aos Hebreus assemelha-se ao koinê literário em suas estruturas sintáticas, aproximando-se do chamado grego clássico e diferindo do koinê vernacular que aparece em outros escritos do Novo Testamento.
} 
mensagem cristã em ambiente plural no sentido religioso e até político. Segundo Lane (1991, p. lxi-lxii), "fatores sociais e religiosos voláteis combinaram-se para minar a estabilidade da igreja doméstica, tornando-a vulnerável a flutuações no clima sociopolítico e religioso".

Apesar de não se saber muito sobre a autoria $\mathrm{da} \mathrm{CH}$, seu discurso somente tem sentido na medida em que é contextualizado nas falas dos interlocutores nele envolvidos. Antes de mais nada, supõe-se que existia, no mínimo, condições de participação dos leitores imediatos da comunidade judaica, posto que alguns temas abordados na $\mathrm{CH}$ são de natureza específica do judaísmo. Ainda, há referências internas que sustentam as interconexões afirmadas no prólogo, como observa Kistemaker (2013, p. 20):

O escritor de Hebreus atrai seus leitores ao citar passagens familiares do AT. Essas passagens, presumivelmente, haviam sido memorizadas pelos leitores; assim, quando ouviam a leitura da $\mathrm{CH}$ no culto público, eles podiam estabelecer uma relação com o conteúdo. As Escrituras do AT, portanto, eram de grande importância para o autor e para os leitores dessa epístola.

Assim, consideremos a seguir o discurso do PH (Hb 1.1-4). A despeito de as falas implícitas ocorrerem abruptamente, sem saudação, elas caracterizam um recurso criativo empregado pelo autor na enunciação para situar seus ouvintes, conforme percebemos na passagem:

1 Havendo Deus, outrora, falado, muitas vezes e de muitas maneiras, aos pais, pelos profetas, 2 nestes últimos dias, nos falou pelo Filho, a quem constituiu herdeiro de todas as coisas, pelo qual também fez o universo. 3 Ele, que é o resplendor da glória e a expressão exata do seu Ser, sustentando todas as coisas pela palavra do seu poder, depois de ter feito a purificação dos pecados, assentou-se à direita da Majestade, nas alturas. 4 tendo-se tornado tão superior aos anjos quanto herdou mais excelente nome do que eles.

Com efeito, o autor insere um ato responsável quando se refere a textos implícitos do AT por meio dos quais assume uma posição inédita na situação de discurso, conquanto continuada em relação à recorrência histórica de fatos similares na Bíblia. Em tese, o autor da $\mathrm{CH}$ se sustenta numa perspectiva excelente de anunciar o que vem depois, perfazendo as diretrizes para uma vida superior mediada pela escrita. Em uma vertente semelhante, Bazerman (2015a, p. 14) sublinha as contribuições da escrita à vida, já que as palavras circulam no tempo e no espaço, "para ajudar-nos a localizar nossas comunicações escritas na história sociocultural, ou seja, de onde vêm e para onde vão as mensagens escritas".

${ }^{9}$ Todas as traduções de fontes em língua estrangeira são de nossa responsabilidade a não ser que haja indicação em contrário. 
Destarte, o autor da $\mathrm{CH}$ não toma palavras mortas e estanques do contexto em que foram proferidas, mas que entram em ação quando correlacionadas com a situação em curso. Nessa ótica, desvela-se uma condição superior do pensamento judaico na medida em que não se cria um enunciado desconexo para a audiência cristã, mas propõe-se mudanças em meio ao estado "fragmentado"10 dos discursos proféticos e de outros locutores precedentes.

Essa forma de dizer parece ter sido familiar aos leitores da $\mathrm{CH}$, pelo que o autor se interpõe entre os discursos precedentes do AT e a situação sociorreligiosa em que se encontravam. Ele passa a usar linguagem retórica para conduzir seus ouvintes ao que descreve como uma instância superior da vida. Em ritmo de sermão, o autor cria vínculos de cooperação entre falantes e ouvintes de épocas diferentes pela mediação de enunciados que se interligam ao propósito comunicativo prenunciado no PH. Medviédev (2016, p. 195) percebe esse tipo de vínculo no fato de que uma "lírica litúrgica podia fazer parte do culto religioso ou, em todo caso, estava próxima da religião”.

Para se ter uma ideia, a partir do $\mathrm{PH}$, o autor faz convergir enunciações precedentes do AT. Ele elabora um esquema de interações entre discursos, mediadas por diálogos abertos de autores da tradição judaica, inserindo-os em seu contexto sociocristão. Por exemplo, em Hb 1.5-14, sete citações em cadeia de eventos distintos, intercaladas por sintagmas introdutores (SI), passam a ser tratadas como parte de um novo ato discursivo, conforme o quadro a seguir:

Quadro 1-Sequência de eventos de fala em Hb 1.5-14

\begin{tabular}{|c|c|c|}
\hline & DISCURSOS & Citações do AT \\
\hline $1.5 \mathrm{a}$ & Pois a qual dos anjos disse jamais: & SI \\
\hline $1.5 \mathrm{~b}$ & "Tu és meu Filho; eu hoje te gerei”? & Sl 2.7 \\
\hline $1.5 \mathrm{C}$ & E outra vez [ele disse]: & SI \\
\hline $1.5 \mathrm{~d}$ & "Eu lhe serei Pai, e ele me será Filho"? & $2 \mathrm{Sm} 7.14$ \\
\hline $1.6 \mathrm{a}$ & E, novamente, ao introduzir o Primogênito no mundo, diz: & SI \\
\hline $1.6 \mathrm{~b}$ & "E todos os anjos de Deus o adorem". & Dt 32.43 \\
\hline $1.7 \mathrm{a}$ & Ainda, quanto aos anjos, diz: & SI \\
\hline $1.7 \mathrm{~b}$ & "Aquele que a seus anjos faz ventos, e a seus ministros, labareda de fogo". & Sl 104.4 \\
\hline $1.8 \mathrm{a}$ & Mas acerca do Filho [diz]: & SI \\
\hline $1.8 \mathrm{~b}-9$ & $\begin{array}{l}\text { "O teu trono, ó Deus, é para todo o sempre; e: Cetro de equidade é o cetro } \\
\text { do seu reino. Amaste a justiça e odiaste a iniquidade; por isso, Deus, } \\
\text { o teu Deus, te ungiu com o óleo de alegria como a nenhum dos teus } \\
\text { companheiros". }\end{array}$ & $\mathrm{Sl} 45.6,7$ \\
\hline $1.10 \mathrm{a}$ & Ainda [diz]: & SI \\
\hline
\end{tabular}

continua

${ }^{10} \mathrm{O}$ termo grego correspondente a "muitas vezes", polimeros, designa o modo diverso ou fragmentado de fazer algo, "relativo ao que ocorre em muitas partes, fragmentário", como afirmam Louw e Nida (2013, p. 547). 
conclusão

\begin{tabular}{|c|l|c|}
\hline \multicolumn{1}{|c|}{ DISCURSOS } & Citações do AT \\
\hline $1.10 b-12$ & $\begin{array}{l}\text { “No princípio, Senhor, lançaste os fundamentos da terra, e os céus são } \\
\text { obra das tuas mãos; eles perecerão; tu, porém, permaneces; sim, todos } \\
\text { eles envelhecerão qual veste; também, qual manto, os enrolarás, e, como } \\
\text { vestes, serão igualmente mudados; tu, porém, és o mesmo, e os teus anos } \\
\text { jamais terão fim”. }\end{array}$ & Sl 102.25-27 \\
\hline $1.13 a$ & Ora, a qual dos anjos jamais disse: & SI 110.1 \\
\hline $1.13 b$ & $\begin{array}{l}\text { "Assenta-te à minha direita, até que eu ponha os teus inimigos por } \\
\text { estrado dos teus pés”? }\end{array}$ & $\begin{array}{l}\text { Conclusão } \\
\text { Não são todos eles espíritos ministradores, enviados para serviço a favor } \\
\text { dos que hão de herdar a salvação? }\end{array}$ \\
\hline
\end{tabular}

Fonte: Elaboração dos autores

A condição de sujeito falante outorgada ao personagem Filho é representativa, na retórica do autor, de discurso superior, divino. Isso estabelece a participação ativa de outros falantes e sugere a criatividade autoral. Este, por sua vez, consolida um ato enunciativo que, mais adiante, considera como o ápice da palavra na Escritura. ${ }^{11}$

Em suma, a fala cristã conflui para a fala do Filho. Também é heterodiscursiva, haja vista suscitar uma pluralidade de encontros de vozes sociais em que sujeitos do discurso cristão interagem na linguagem. De acordo com Bakhtin (2015b, p. 67), os atos consensuais também integram o universo heterodiscursivo das vozes sociais, ou seja, "todas elas podem ser confrontadas, podem completar umas às outras, podem contradizer umas às outras, podem ser correlacionadas dialogicamente".

Para o autor da $\mathrm{CH}$, "nestes últimos dias [Deus], nos falou pelo Filho". Falou e tem falado? Eis a questão do $\mathrm{PH}$ que o legitima como discurso antigo, contudo ainda válido em condições díspares de vida. Os recursos linguísticos são importantes para a compreensão da escrita, e esta só tem sentido quando se alinha a discursos da vida. O código abstrato não é o princípio, pois a retórica da língua escrita "constrói-se para a ação, em vez de para a descrição estática", conclui Bazerman (2015a, p. 22), logo, o código é "um recurso a ser empregado em situações concretas com objetivos e atividades individuais e coletivos, seu objeto primeiro".

De mais a mais, a escrita do enunciado da $\mathrm{CH}$ não é um objeto fixo de apreciação, mas tem seu referente na dinamicidade da própria fé e esta, por sua vez, tem sentido em si mesma quando se relaciona com contextos subsequentes; a fé por um lado é um dado, mas, por outro, interação dialógica; é expressa na escrita como resultante de falas situadas em contexto peculiar. Por essa razão, o discurso cristão é relevante para a vida, pois representa ação.

\footnotetext{
${ }^{11} \mathrm{Hb}$ 4.12: "Porque a palavra de Deus é viva, e eficaz, e mais cortante do que qualquer espada de dois gumes, e penetra até ao ponto de dividir alma e espírito, juntas e medulas, e é apta para discernir os pensamentos e propósitos do coração."
} 
Depreende-se, então, que a proposta retórica da $\mathrm{CH}$ na linguagem persuasiva não é um mero produto da transposição da fala à escrita, mas um indicativo da condição de letramento social dos leitores imediatos, aliada a sua participação ativa nos eventos sociocristãos. O letramento social, nesse caso, não só caracteriza uma familiaridade dos leitores com a língua falada, mas o alinhamento dos sujeitos às situações da vida com as quais eles interagem

Segundo Kleiman (2008), nas práticas de oralidade, os ouvintes correlacionam os conteúdos textuais com fatos familiares pelos quais suas mentes se ligam a outros eventos. Os agentes sociais se orientam no texto em curso porque já participam de outros similares, sob uma condição de letramento, isto é, de oralidade letrada, ao mesmo tempo de assimilação de prática discursiva letrada. Analogamente, a leitura da $\mathrm{CH}$ sugere a participação de outras vozes na comunidade discursiva centrada nos aspectos de valoração do agente de fala implícito, o Filho, como sujeito ativo e moderador de discursos para onde convergem as falas.

Outro ponto notável no PH é a questão dos gêneros que o integram. Uma vez que estamos refletindo sobre a ação letrada em discurso cristão, devemos considerar a intergenericidade inerente a este discurso. Concernente a essa questão, Bakhtin comenta que os "gêneros cristãos" são amplos e bem mais complexos do que se depreende:

os principais gêneros [...] da literatura cristã antiga - o evangelho, os "feitos dos apóstolos", o "apocalipse" e a "hagiografia dos santos e mártires” - estão relacionados à aretologia antiga. [...] Nesses gêneros, especialmente nos inúmeros "evangelhos" e "feitos", elaboram-se as clássicas síncrises dialógicas cristãs [...]. A literatura [...] cristã incorporou também os gêneros cognatos: o simpósio [...] e o solilóquio. (BAKHTIN, 2015a, p. 154).

Em outras palavras, a $\mathrm{CH}$ é essencialmente um complexo gênero sermão que serve a propósitos exortativos e de elogios, porque "o sermão [..] é a parte principal da adoração". (KISTEMAKER, 2013, p. 556). Este sermão forma um grande encômio (elogio) da oratória clássica (OLBRICHT, 1993). Nesse viés, essa intercalação expressa uma relação intergenérica com o gênero encômio.

Por subscrever o evento dos "últimos dias", o sermão retrata o drama final em prosa, não por linguagem satírica, mas ao representar as falas alheias, o faz à semelhança de um gênero menipeia, já que este "se caracteriza pela síncrise (ou seja, o confronto) precisamente dessas 'últimas atitudes no mundo' já desnudadas”, conforme Bakhtin (2015b, p. 132).

Aliadas a esses gêneros, as técnicas retóricas inserem discursos introdutórios. $\mathrm{Na} \mathrm{CH}$, o autor descreve em poucas palavras a situação de discurso sob a forma protocolar de "gênero introdutório", como prólogo ou proêmio. Vale ressaltar que uma distinção inequívoca entre os termos "proêmio", "exórdio", "prólogo" ou "prefácio" é inviável, é forçada, do ponto de vista dos usos efetivos do gênero, conforme Bezerra (2006). 
Aqui, o gênero introdutório é composto sob a égide dos gêneros de discursos cristãos. Grosso modo, a confissão (individual e coletiva) norteia os principais gêneros nos eventos de letramento nos quais a fé cristã se insere. A partir disso, pensamos o $\mathrm{PH}$ como uma promoção de atividades regulares de escrita e leitura do AT sob condições de "letramento confessional".

Pelo reconhecimento de determinados aspectos de gêneros introdutórios, identificam-se fios ideológicos que unem o discurso cristão ao precedente. Desse modo, contextos são interligados pela reativação da memória do leitor, à guisa de alusões profundas a textos revisitados do AT, como sugere a expressão do PH: "Havendo Deus, outrora, falado, muitas vezes e de muitas maneiras, aos pais, pelos profetas".

Assim, em Hebreus, o gênero prólogo é um ponto de acentuação da fala que antecipa o sentido das palavras ao promover interações sociais. Sobre isso, Bezerra (2017, p. 83) chama a atenção para os gêneros introdutórios, que, a propósito de sua multiplicidade, permitem "dar voz a uma quantidade maior de atores sociais", em discursos outros. O PH é similar a um prelúdio por supor conexões de discursos sociais.

Em suma, ao se fazer referência à fala, à escrita e, em alguns casos, à leitura, tem-se em conta que essas modalidades integram processos de interações sociocristãs, na produção e recepção do texto da $\mathrm{CH}$, como enunciado concreto que serve a propósitos específicos. A despeito de o $\mathrm{PH}$ exaurir um discurso protocolar que foca nas afirmações inerentes ao texto bíblico, é imperioso relacionar seu discurso original com as situações emergentes de mudanças sociais, de empreendimentos feitos em contextos de significações plurais.

\section{O PRÓLOGO DE HEBREUS NA TRANSPOSIÇÃO DA ESCRITA ÀS FALAS}

Aqui, discutiremos a sustentação da fala em atividades subsequentes à escrita. Ocorre que os textos bíblicos em geral refletem o modo de viver judaico-cristão. As práticas de leitura destes textos sugerem que os participantes sejam familiarizados com o conteúdo de sentido sagrado. Em outras palavras, os sujeitos são letrados na fé cristã. Bazerman (2015a, p. 58)

lembra que os textos sagrados antigos operam como atuais em sua força e significação, pois "tendem a manter momentos e arranjos anteriores no âmbito de circunstâncias em transição cambiantes". Conforme Bazerman, "a relevância e a força desses textos duradouros se apoiam em instituições e práticas culturais e sociais igualmente duradouras" (p. 58).

Quanto aos textos bíblicos, deve-se notar as disjunções entre as línguas para não correr o risco de se nivelar dizeres. Beaugrande (1997, p. 372) observa bem que "a necessidade de coincidências torna a tradução um modo eminentemente problemático para a intertextualidade". Além disso, em consonância com Bazerman (2015a, p. 58), os "eventos e contextos mutáveis trazem a mutabilidade temporal à leitura", de modo que "quando lemos textos fora de seu ambiente cultural e de seu tempo específico, também estamos envolvidos em novas 
atividades no nosso momento da leitura". Nesse sentido, Marcuschi (2008) acrescenta que a ideia produtiva de intertextualidade é implicada na heterogeneidade das formas variadas dos discursos outros que se impõem num texto. Tudo leva a crer que a memória textual não se fixa na palavra nem no evento passado, mas é um desdobramento de ambos à vida.

Em acréscimo a tudo isso, as condições de letramento estão em constante mudança em todo grupo social. Logo, a questão central é: como relacionar discursos entre a escrita do $\mathrm{PH}$ e a recepção das palavras nele contidas na diversidade das tradições cristãs que inserem práticas de letramentos especificas? Decerto, a resposta a essa questão se encontra numa abordagem responsável das práticas axiológicas mais valoradas por determinada comunidade.

Em resumo, a recepção dessas palavras abre espaço para ações, conforme um ethos da comunidade cristã. Para Vanhoozer (2018, p. 142), "o ethos cria a ecologia moral, o contexto para a reflexão e ação”. Destarte, as práticas axiológicas se prestam à aplicação do texto escrito na situação factual dos leitores, aproximando-se das práticas de letramento voltadas para o modelo ideológico de letramento, por se levar em conta o contexto de enunciação.

É oportuno lembrar que a $\mathrm{CH}$ está vinculada ao seu conteúdo de sentido no contexto original, nem se exime de interações subjacentes às falas de seus atores sociais. Conquanto essas vozes reflitam as ações da experiência da fé, também representam, na modalidade escrita, encontros de horizontes, de pessoas articuladas com seus momentos de vida.

Bazerman (2015a, p. 62) compreende que contextos distantes se relacionam através da continuidade das instituições - ou como já pontuamos aqui, da tradição de fé -, de sorte que "até mesmo as mais estáveis das escrituras sagradas [e.g., a Bíblia] são parte de religiões em transformação em mundos que se modificam, cujas significações, portanto, também se modificam”. É claro que Bazerman (2015a) se refere às situações que emanam do cotidiano, que carecem de respostas contextualizadas, em consonância com situações novas emergentes da vida. Além do mais, valores ideológicos, elementos que integram o construto social de um grupo tendem a permanecer, são, nesse sentido, inegociáveis, como em parte é a fé.

As referências ao contexto são uma questão de indicialidade, indicada nas amostragens etnometodológicas, de acordo com Garfinkel (2018), e são traços de situações reconhecíveis no discurso situado. $\mathrm{Na} \mathrm{CH}$, a indicialidade é evidente nas formas linguísticas expressivas (adverbiais) que operam como modificadores de verbos discendi: "ele fala", "ainda fala", "ao que fala", "em outro lugar também diz", "enquanto se diz", "quando ele diz”. A ilustração a seguir mostra o verbo grego laleo (falar) ${ }^{12}$ e os significados em contextos de uso na $\mathrm{CH}$.

\footnotetext{
${ }^{12} \mathrm{O}$ termo grego laleo é empregado como verbo discendi (que expressa o ato de dizer) e ocorre 16 vezes na $\mathrm{CH}$. Em todos os casos indica situações sociocomunicativas, atos de fala. Louw e Nida (2013, p. 356) definem o verbo como "dizer", "contar", "falar" ou "conversar", com possível implicação de uso mais informal.
} 


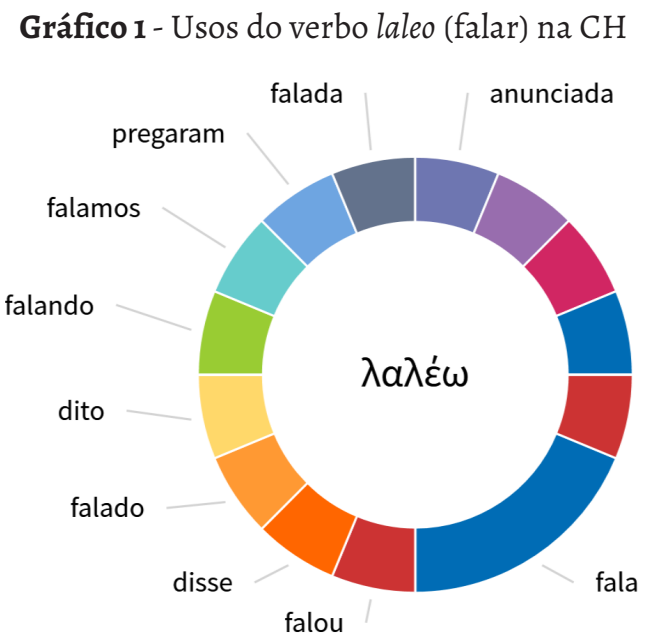

Fonte: Software Bíblico Logos (2021)

Portanto, a convergência das falas inseridas na escrita da $\mathrm{CH}$ opera como um conjunto de elementos concernentes à fé que transpassam o tempo, um continuum de contextos sociais intercomunicáveis. Mas a fala canalizada nos atos do Filho (Hb 1.1-4) não cala outras vozes da comunidade cristã, pelo contrário, as torna afinadas com o tom do discurso pretendido pela força da palavra, mantendo-se na tradição (por exemplo, em $\mathrm{Hb}$ 1.4-14), antes fragmentada.

Sumariamente, mesmo em se tratando de texto escrito, é concebível haver interações dialógicas. Volochinov (2017, p. 219) argumenta que "um livro, ou seja, um discurso verbal impresso também é um elemento de comunicação discursiva. Esse discurso é debatido em um ato dialógico direto e vivo, e, além disso, é orientado para uma percepção ativa: uma análise minuciosa e uma réplica interior".

Na perspectiva contextual, ainda se faz necessário perceber as pontes entre horizontes mais amplos, ressaltando-se, sobretudo, as condições de leitura ante a dinâmica das interações sociais. Ao anunciar que "nestes últimos dias, nos falou pelo Filho", de certo modo o autor da $\mathrm{CH}$ estabelece um vínculo permanente no discurso do Filho, como inauguração da era derradeira.

Em seguida, serão abordadas questões relacionadas à interação das falas, com base na Teoria da ação letrada de Bazerman (2015b), segundo a qual as forças sociais exercem influência sobre as atividades de escrita e de fala, tornando-as modalidades complementares de sentido da enunciação. Nessa direção, Bazerman (2015b, p. 13) afirma que

a arte da escrita retórica supõe que o escritor aumente a influência ou efeito do tipo que ele desejar sobre os leitores. E a arte da leitura retórica supõe que cada leitor localize, interprete e avalie o que está sendo oferecido, com base em suas posições, interesses e compreensão e em seus próprios propósitos. 
Ainda sobre a escrita retórica, Miller (2012, p. 39, 41) insiste que os gêneros são reflexos históricos de atos recorrentes, e que adquirem o "significado da situação e do contexto social em que essa situação surgiu" e dessa forma "ajudam a construir a substância de nossa vida cultural [...], servem de chave para entender como participar das ações de uma comunidade".

Assim, as interações sociais são indícios de atividades de sujeitos situados no tempo e no espaço, isto é, na linguagem. Nas palavras de Bazerman (2015b, p. 15): "toda interação letrada está inserida em momentos particulares nas possibilidades mutáveis da consciência e das relações humanas". Isso amplia a consciência histórica de indivíduos situados. Conquanto em certos casos os usos dos textos da Bíblia sejam "para manter convenções sociais relativas à afirmação do poder e à validação do conhecimento", conforme Street (2014, p. 51).

Por outro lado, a expressão "nestes últimos dias" é indicial por refletir ações de sujeitos ativos no tempo. Garfinkel (2018, p. 123) traduz essas marcas no campo das atividades cotidianas, nas quais "o membro da sociedade usa as expectativas contextuais como esquema de interpretação". Assim, o aqui-e-agora é transformado e ampliado nas e pelas palavras do discurso do Filho. Bazerman (2015b, p. 19) argumenta que "a linguagem facilita a representação de objetos distantes no aqui e agora intersubjetivo da conversa”. Miller (2012, p. 122) lembra corretamente que "o texto bíblico não pode ser totalmente compreendido sem a compreensão de sua natureza oral".

É razoável que os conhecimentos implícitos no $\mathrm{PH}$ integrem atos contínuos, ativos na cadeia de intertextos constitutivos das tradições cristãs. Segundo Bazerman (2015b, p. 189), o mundo do texto é produto de indexação de conteúdos inteligíveis e "a dependência de textos anteriores faz parte da intertextualidade que permeia o mundo letrado". Quanto às práticas cristãs, a leitura perfaz condições de letramento privilegiadas, exerce papel de socialização em ciclos letrados ao introduzir seus participantes em eventos similares às práticas pedagógicas para construir sentidos a partir da compreensão de textos.

Resta-nos mostrar a relevância do texto da $\mathrm{CH}$ à prática letrada para o estabelecimento de um pensamento concreto. Marcuschi (2008, p. 84) afirma que "entre o discurso e o texto está o gênero, que é aqui visto como prática social e prática textual-discursiva”. Bazerman (2015b, p. 191) recorre à intertextualidade, como fenômeno linguístico que, apesar de ocorrer no âmbito textual, "tem grandes implicações sociológicas e psicológicas. A intertextualidade fornece mecanismos para a formação de crenças comuns e consciências individuais".

Quando o escritor insere conteúdos no texto, objetiva manter o controle do modo de raciocinar do leitor, e neste, por seu turno, elementos do cotidiano social são (re)ativados em sua mente, formando, cada vez mais, um sujeito interativo. Nessa ótica, pôr em movimento os conteúdos escritos significa identificar-se com eles, relacionar-se com situações discerníveis. A leitura transporta sujeitos ativos para o mundo do texto, e não apenas isso, ela os introduz no mundo de interações dialógicas, no mundo de desejos comuns. 
A ação letrada, por sua vez, multiplica os pontos de interseção entre as culturas, pois insere "o indivíduo que participa de forma significativa de eventos de letramento e não apenas aquele que faz um uso formal da escrita", conforme Marcuschi (2010, p. 25).

Consequentemente, conclui Bazerman (2015b, p. 206), as invenções letradas facilitam uma maior compreensão das atividades referentes às "comunidades de crença definidas pelo comprometimento com os textos sagrados e suscetíveis a cismas com relação ao significado dos textos". De mais a mais, em Hebreus, a ação letrada torna os participantes da comunidade cristã mais envolvidos com o cerne de sua mensagem, na Palavra e ação do Filho.

Tendo em vista as considerações feitas sobre letramentos sociais até aqui, entende-se que Hebreus sugere um espaço complexo de interações sociais, engendrado por concepções múltiplas, um enunciado concreto em sua essência. O aspecto focal do PH é a exauribilidade dos acontecimentos anteriores na ótica cristã, num evento de fala situada - "hoje" - do Filho. Bakhtin (2016, p. 78) afirma que "a atitude humana é um texto em potencial e pode ser compreendida (como atitude humana e não ação física) unicamente no contexto dialógico da própria época (como réplica, como posição semântica, como sistema de motivos)".

No evento introdutório (protocolar), a confiabilidade da fala do Filho é potencializada dentro de um processo de nominação. As palavras (especialmente, adjetivos) são associadas às ações do Filho, mas recortadas de textos extrinsecamente correlacionados, e acabam por conferir um colorido todo especial ao $\mathrm{PH}$.

Então, não é sem razão ratificar este ponto de vista, a propósito de o escritor pretender só situar seus leitores imediatos em um contexto social mais amplo, dadas as suas condições letradas. Não o faz em benefício próprio, mas para indicar na fala do Filho a convergência dos discursos do cotidiano pela mediação de outros interlocutores presumivelmente reconhecíveis.

$\mathrm{O}$ cerne do prólogo da $\mathrm{CH}$ é a palavra, fundamentada no sentido que se comunica à vida; palavra que se (a)firma cada vez que é pronunciada nos mais variados círculos letrados, como a resultante de forças sociais situadas em contextos interdiscursivos, contínuos.

\section{TóPICOS DE AÇÃo LETRADA NO PRÓLOGO DA CARTA AOS HEBREUS}

No nível macro de estrutura do discurso, Hb 1.1-4 é composto por textos híbridos que representam ecos do AT usados pela tradição judaico-cristã, referentes a eventos precedentes sob os quais são montados temas teológicos da fé cristã, como o vemos em segmentos que correspondem a conceitos da teologia ${ }^{13}$ sistemática:

\footnotetext{
${ }^{13} \mathrm{~A}$ teologia sistemática trata de temas específicos do pensamento cristão. Por exemplo, a protologia refere-se a temas relacionados com o estudo da Criação; a escatologia trata dos últimos acontecimentos; a soteriologia aborda a obra da salvação; e a cristologia estuda a pessoa e a obra de Cristo.
} 
Quadro 02 - Segmentação temática do $\mathrm{PH}$

\begin{tabular}{|c|c|c|}
\hline VERSO & SEGMENTAÇÃO DO PH & TEMAS \\
\hline $\mathrm{Hb} 1.1$ & $\begin{array}{l}\text { Havendo Deus, outrora, falado, muitas vezes e de muitas maneiras, } \\
\text { aos pais, pelos profetas, }\end{array}$ & TEOLOGIA \\
\hline $\mathrm{Hb} 1.2 \mathrm{a}$ & nestes últimos dias, nos falou pelo Filho, & ESCATOLOGIA \\
\hline $\mathrm{Hb} 1.2 \mathrm{~b}$ & a quem constituiu herdeiro de todas as coisas, & CRISTOLOGIA \\
\hline $\mathrm{Hb} 1.2 \mathrm{C}$ & pelo qual também fez o universo. & CRISTOLOGIA \\
\hline $\begin{array}{l}\mathrm{Hb} \\
1.3 \mathrm{a}-\mathrm{b}\end{array}$ & $\begin{array}{l}\text { Ele, que é o resplendor da glória e a expressão exata do seu Ser, } \\
\text { sustentando todas as coisas pela palavra do seu poder, }\end{array}$ & CRISTOLOGIA \\
\hline $\mathrm{Hb} 1.3 \mathrm{C}$ & depois de ter feito a purificação dos pecados, & SOTERIOLOGIA \\
\hline $\mathrm{Hb} 1.3 \mathrm{~d}$ & ele se assentou à direita da Majestade nas alturas, & CRISTOLOGIA \\
\hline $\mathrm{Hb} 1.4$ & $\begin{array}{l}\text { tendo-se tornado tão superior aos anjos quanto herdou mais excelente } \\
\text { nome do que eles. }\end{array}$ & CRISTOLOGIA \\
\hline
\end{tabular}

Fonte: Elaboração dos autores

Do ponto de vista formal, os paralelismos de sequências linguísticas mostram o quanto a regularidade nessas formas é reconhecível como uma prática letrada dos indivíduos, não só na oralidade de textos em encontros comunais, mas sobretudo na identificação do conteúdo em destaque que veicula o objeto de sentido de uma enunciação. Vejamos esses destaques.

$\mathrm{Em} \mathrm{Hb}$ 1.1-4, os eventos inerentes a um quadro teológico geral concentram uma forma de cristologia e soteriologia, estribadas na pessoa e obra de Cristo. Hb 1.1 é uma referência a acontecimentos da teologia no sentido amplo, cf. Dn $2.28 .{ }^{14} \mathrm{Hb} 1.2 \mathrm{a}$ retrata aspectos escatológicos da teologia relacionados com os últimos dias, cf. Jl 2.28-29. ${ }^{15} \mathrm{Hb} 1.2 \mathrm{~b}, \mathrm{Hb} 1.2 \mathrm{c}$ e Hb 1.3a-b são alusivos a textos similares a Dn 7.13-14 ${ }^{16}$ no AT e Cl 1.15-17 $7^{17}$ no NT. Hb 1.3d e Hb 1.3c apontam, respectivamente, para os versos 1 e 4 do $\mathrm{Sl} 110 .{ }^{18} \mathrm{Enfim}, \mathrm{Hb} 1.4$ dá início a um processo de síncrise (comparação) entre o personagem Filho e os anjos em sete citações diretas do AT (Sl 2.7; 2 Sm 7.14; Dt 32.43; Sl 104.4; Sl 45.6,7; Sl 102.25-27 e Sl 110.1), conforme já apresentado no quadro 1.

${ }^{14}$ Dn 2.28: "Mas há um Deus no céu, o qual revela os mistérios, pois fez saber ao rei Nabucodonosor o que há de ser nos últimos dias."

${ }^{15} \mathrm{Jl}$ 2.28-29: "E acontecerá, depois, que derramarei o meu Espírito sobre toda a carne; vossos filhos e vossas filhas profetizarão, vossos velhos sonharão, e vossos jovens terão visões; até sobre os servos e sobre as servas derramarei o meu Espírito naqueles dias."

${ }^{16}$ Dn 7.13-14: "Eu estava olhando nas minhas visões da noite, e eis que vinha com as nuvens do céu um como o Filho do Homem, e dirigiu-se ao Ancião de Dias, e o fizeram chegar até ele. Foi-lhe dado domínio, e glória, e o reino, para que os povos, nações e homens de todas as línguas o servissem; o seu domínio é domínio eterno, que não passará, e o seu reino jamais será destruído."

${ }^{17} \mathrm{Cl}$ 1.15-17: "Este é a imagem do Deus invisível, o primogênito de toda a criação; pois, nele, foram criadas todas as coisas, nos céus e sobre a terra, as visíveis e as invisíveis, sejam tronos, sejam soberanias, quer principados, quer potestades. Tudo foi criado por meio dele e para ele. Ele é antes de todas as coisas. Nele, tudo subsiste."

${ }^{18}$ Sl 110.1: "Disse o Senhor ao meu senhor: Assenta-te à minha direita, até que eu ponha os teus inimigos debaixo dos teus pés." Sl 110.4: "O Senhor jurou e não se arrependerá: Tu és sacerdote para sempre, segundo a ordem de Melquisedeque." 
Observemos esse paralelismo na citação do Salmo 8.4 em Hb 2.6, na expressão: "Que é o homem, que dele te lembres? Ou o filho do homem, que o visites?".

Quadro 03 - Paralelismo sinonímico em $\mathrm{Hb} 2.6$

\begin{tabular}{|c|c|c|}
\hline $\mathrm{Hb}$ & Segmentos textuais em Hb 2.6 & \multicolumn{1}{c|}{ Paralelismos } \\
\hline $2.6 \mathrm{a}$ & Que é o homem, & 6a e 6c homem e filho do homem \\
\hline $2.6 \mathrm{~b}$ & que dele te lembres? & \\
\hline $2.6 \mathrm{c}$ & Ou o filho do homem, & 6b e 6d lembres e visites \\
\hline $2.6 \mathrm{~d}$ & que o visites? & \\
\hline
\end{tabular}

Fonte: Elaboração dos autores

Nesse sentido, o $\mathrm{PH}$ pode ser percebido em tópicos de padrão simétrico ou quiástico ${ }^{19}$ do discurso, no que diz respeito aos agentes de falas designados por eventos de ação letrada, como vemos a seguir na estrutura quiástica proposta por Ebert:

1-2a $\rightarrow$ O Filho contrastou com os profetas

$1.2 \mathrm{~b} \rightarrow$ Filho como herdeiro messiânico

$1.2 \mathrm{c} \rightarrow$ A obra criativa do Filho

$1.3 \mathrm{a}-\mathrm{b} \rightarrow$ O relacionamento mediador triplo do Filho com Deus

$1.3 \mathrm{C} \rightarrow$ A obra redentora do Filho

$1.3 \mathrm{~d} \rightarrow$ O Filho como rei messiânico

$1.4 \rightarrow$ O Filho contrastado com os anjos

Nesse arranjo, nota-se não apenas a regularidade da forma e conteúdo, mas aquilo que o autor da $\mathrm{CH}$ demarca no centro do discurso introdutório ao relacionar estrutura, conteúdo e temas conhecidos. Portanto, a nosso ver, a expressão semântica dessa enunciação se aproxima do elemento central do quiasmo.

A interpretação desses ecos ao AT ocorre ex post facto, como "não-coincidência" da ação de dizer. O verso 1 refere-se a eventos anteriores, vistos como atos de fala de Deus pelos profetas; o verso 2 alude a fatos recorrentes descritos na fala implícita do Filho; e os versos 3 e 4 sugerem os eventos presentes nas vozes evocadas na situação de discurso.

A fala autoral traduz a voz de Deus nos textos do AT, tal qual um ato profético pelo qual utiliza de fragmentos de falas alheias apropriados a seu propósito comunicativo. Começando por $\mathrm{Hb}$ 1.1, em que as falas alheias remontam à agentividade da fala de Deus. Em Hb 1.2a, as vozes alheias são protocoladas na fala atual do Filho, "nestes últimos dias", que se torna o

\footnotetext{
${ }^{19} \mathrm{O}$ termo quiasmo, da letra grega chi, é uma estrutura linguística que relaciona as subunidades de um texto numa sequência, e.g., A-B-C-D-E-E'-D'-C'-B'-A', um tipo de paralelismo cruzado (invertido). Algumas vezes, o padrão quiástico é concêntrico, "tem um elemento no centro que não apresenta elemento paralelo, [...] como A-B-C-B'-A', no qual o elemento C é o ponto central, o elemento de gravidade, e a base do texto como um todo", segundo Gorman (2017, p. 113).
} 
agente (implícito). Em $\mathrm{Hb} 2 \mathrm{~b}-3$, acentuam-se os atributos e os feitos (objetos de sentido) pelos quais o falante, o Filho, é qualificado como tal.

Em suma, o PH modaliza dizeres assim: Hb 1.1-2a reflete o clímax da comunicação divina sob ação letrada em forma de verbo discendi; Hb 1.2b-3 consolida uma estrutura de objetos de sentido da substância viva do discurso (a palavra "encarnada" na ação do Filho). No primeiro caso, a dimensão verbo-estilística de Hb 1.1-2a estabelece uma ordem de fala na $\mathrm{CH}$. Pelo que o autor traz à baila quatro posições de fala em relação ao AT: (1) as alusões a discursos proféticos para embasar o enunciado; (2) o discurso implícito de Deus; (3) o discurso implícito do Filho como releitura; e (4) o discurso criativo do autor para interpretar as vozes evocadas nos discursos outros.

Isso configura um quadro amplo de interações sociorreligiosas entre autores alheios, sob a mediação do autor da $\mathrm{CH}$. Contudo, o ato criativo deste delimita a agentividade nas falas e ações oriundas de "conversas" (interações) entre o Pai e o Filho. Aqui, demarca-se o espaço-tempo da fala divina, nos eventos finais de "os últimos dias", na irrupção da era cristã.

A acepção verbal em "nos falou pelo Filho" é indireta, implica um inventário de ações que integram o conteúdo de sua obra, em Hb 1.2b-3, como vemos a seguir. Em Hb 1.2b-3, o atributo da fala é do Filho especificado numa estrutura semântica do $\mathrm{PH}$. A posição valorativa do autor insere as substâncias (conteúdos) do discurso referentes ao status elevado na nominação do Filho mediante enlace adjetival. O quadro a seguir mostra que no todo Hb $1.2 \mathrm{~b}-4$ delimita o papel de falante atribuído ao Filho, referentes a sua participação em ações do AT antes designadas a Deus.

Quadro 04 - Agentes de fala no exórdio

\begin{tabular}{|c|l|c|l|}
\hline AGENTE & \multicolumn{1}{|c|}{ AÇÃO PRINCIPAL } & COAGENTE & \multicolumn{1}{|c|}{ REFLEXO DA AÇÃO } \\
\hline DEUS & constituiu & FILHO & herdeiro de todas as coisas \\
\hline DEUS & também fez o universo & FILHO & pelo qual \\
\hline FILHO & é o resplendor & DEUS & da glória de Deus \\
\hline FILHO & a expressão exata & DEUS & do seu ser \\
\hline FILHO & sustentando todas as coisas & FILHO & pela palavra do seu poder \\
\hline FILHO & purificação dos pecados & DEUS & (estado superior das coisas) \\
\hline FILHO & ele se assentou à direita & DEUS & da majestade nas alturas \\
\hline FILHO & tendo-se tornado tão superior & ANJOS & aos anjos \\
\hline FILHO & herdou mais excelente nome & ANJOS & do que eles \\
\hline
\end{tabular}

Fonte: Elaboração dos autores

Essa cadeia forma um elo adjetival de conteúdos da substância viva da fé textualmente coerentes com os eventos precedentes, ora remidos como ecos de discursos outros. É razoável 
depreender nos ecos amplificados do AT as ações letradas dos participantes da $\mathrm{CH}$, no fato de a arte da escrita retórica do autor influenciar uma leitura retórica situada dos leitores. É de se esperar que as expressões ideologicamente potencializadas na cadeia de adjetivos vinculados ao nome do Filho ativem a memória sociocristã através das vozes que já reverberam na audiência. É ainda razoável considerar que a cadeia de adjetivos no $\mathrm{PH}$ sugere uma remissão ou ao menos alusão à Carta de Paulo aos Colossenses, como separamos em partes o excerto Cl 1.15-17.

\begin{abstract}
${ }^{1.15 a}$ Este é a imagem do Deus invisível, ${ }^{1.15 b}$ o primogênito de toda a criação; ${ }^{1.16 a}$ pois, nele, foram criadas todas as coisas, nos céus e sobre a terra, as visíveis e as invisíveis, ${ }^{1.16 b}$ sejam tronos, sejam soberanias, quer principados, ${ }^{1.16 c}$ quer potestades. ${ }^{1.16 \mathrm{~d}}$ Tudo foi criado por meio dele e para ele. ${ }^{1.17}$ Ele é antes de todas as coisas. Nele, tudo subsiste.
\end{abstract}

Quadro 05 - Comparação de expressões entre $\mathrm{Hb}$ 1.1-4 e Cl 1.15-17

\begin{tabular}{|c|c|c|c|}
\hline $\mathrm{Hb}$ & Segmentos do PH & $\mathrm{Cl}$ & Segmentos em $\mathrm{Cl}$ 1.15-17 \\
\hline $1.2 b$ & Constituiu herdeiro de todas as coisas & $1.15 b$ & o primogênito de toda a criação \\
\hline $1.2 \mathrm{C}$ & Pelo qual também fez o universo & $1.16 \mathrm{a}$ & $\begin{array}{c}\text { Pois nele, foram criadas todas as coisas, nos } \\
\text { céus e sobre a terra }\end{array}$ \\
\hline $1.3 a$ & $\begin{array}{c}\text { Ele, que é o resplendor da glória e a expressão } \\
\text { exata do seu Ser, }\end{array}$ & $1.15 \mathrm{a}$ & Este é a imagem do Deus invisivel \\
\hline $1.3 b$ & $\begin{array}{l}\text { sustentando todas as coisas pela palavra do } \\
\text { seu poder. }\end{array}$ & 1.17 & $\begin{array}{l}\text { Ele é antes de todas as coisas. Nele, tudo } \\
\text { subsiste }\end{array}$ \\
\hline $1.3 \mathrm{~d}$ & $\begin{array}{c}\text { ele se assentou à direita da Majestade nas } \\
\text { alturas, }\end{array}$ & $1.16 \mathrm{~b}$ & $\begin{array}{l}\text { sejam tronos, sejam soberanias, quer } \\
\text { principados, }\end{array}$ \\
\hline 1.4 & $\begin{array}{l}\text { tendo-se tornado tão superior aos anjos } \\
\text { quanto herdou mais excelente nome do } \\
\text { que eles. }\end{array}$ & $1.16 \mathrm{c}$ & $\begin{array}{l}\text { [criadas as coisas invisíveis] quer } \\
\text { potestades. }\end{array}$ \\
\hline
\end{tabular}

Fonte: Elaboração dos autores

Assim, em Hb 1.2b-3, o autor assume uma posição de fala quase proverbial, de modo que a ênfase adjetival é exofórica, haja vista que ele se apropria de objetos localizados na situação extraverbal. O efeito dessa presença alheia configura uma estética nova do dizer no discurso autoral marcada por um certo distanciamento. Por exemplo, a expressão "purificação dos pecados" é existencial, refere-se ao estado superior (perfeito) das coisas, e dá uma feição essencialmente cognitiva e retórica a $\mathrm{Hb}$ 1.2b-3, relacionada a partes profundas da posição dogmática inacabada quanto à purificação no AT.

Toda essa ação letrada em $\mathrm{Hb}$ 1.1-4, além de cumprir a função introdutória como PH, corrobora a ênfase adjetival na presença genérica intercalada. Ademais, o discurso é marcado por tópicos da "confissão comunal", na perspectiva do autor, como vemos no quadro a seguir. 
Quadro 06 - Tipologia de discursos no PH

\begin{tabular}{|c|l|c|}
\hline VERSO & \multicolumn{1}{|c|}{ GÊNERO INTRODUTÓRIO: PRÓLOGO } & TIPOLOGIA \\
\hline Hb 1.1 & $\begin{array}{l}\text { Havendo Deus, outrora, falado, muitas vezes e de muitas maneiras, } \\
\text { aos pais, pelos profetas, }\end{array}$ & CONFISSÃO \\
\hline Hb 1.2a & nestes últimos dias, nos falou pelo Filho, & CONFISSÃO \\
\hline Hb 1.2b & a quem constituiu herdeiro de todas as coisas, & CONFISSÃO \\
\hline Hb 1.2c & pelo qual também fez o universo. & CONFISSÃO \\
\hline $\begin{array}{c}\text { Hb } \\
\text { 1.3a-b }\end{array}$ & $\begin{array}{l}\text { Ele, que é o resplendor da glória e a expressão exata do seu Ser, } \\
\text { sustentando todas as coisas pela palavra do seu poder, }\end{array}$ & ENCÔMIO \\
\hline Hb 1.3c & $\begin{array}{l}\text { depois de ter feito a purificação dos pecados, } \\
\text { Hb 1.3d }\end{array}$ & ele se assentou à direita da Majestade nas alturas, \\
\hline ten 1.4 & $\begin{array}{l}\text { tendo-se tornado tão superior aos anjos quanto herdou mais excelente } \\
\text { nome do que eles. }\end{array}$ & CONFISSÃO \\
\hline
\end{tabular}

Fonte: Elaboração dos autores

Os tópicos da confissão no PH são realçados por elogio (gênero encômio) em Hb 1.3a, e pressupõem um coro confessional implícito, visto que as proposições valorativas elencadas em $\mathrm{Hb}$ 1.2b-3 soam familiares à audiência da $\mathrm{CH}$. Então, o $\mathrm{PH}$ promove eventos de letramento que perfazem o protagonismo da fala do Pai através do Filho em declarações recíprocas sobre as quais o autor lança olhar reflexivo ao envolver outros discursos na produção/recepção do enunciado.

Portanto, a julgar pela proeminência do discurso do $\mathrm{PH}$, ao ritmo sermônico, Hebreus se abre para práticas de letramento subsequentes nas múltiplas tradições cristãs, reivindicando para si uma leitura proveitosa para outros eventos cúlticos na igreja, seja no ensino teológico em diferentes instituições (escolas, seminários), seja nas práticas letradas de evangelização.

\section{Considerações finaIS}

Neste estudo, observamos que as práticas de letramento se mostram recorrentes nas diversas camadas de interações sociocristãs. A forma prosaica como a $\mathrm{CH}$ sugere interações de fala é bem singular no NT. Concluímos que a fala é um aspecto integrado na escrita da $\mathrm{CH}$, operando interações entre as vozes evocadas pelo escritor em intertextos da tradição judaico-cristã, como reação à situação de vida dos ouvintes imediatos, os quais já participam de eventos de letramento.

Assim, como ato sermônico composto, Hebreus marca encontros de visões complexas, estabilizadas conforme o propósito genérico. Em outros termos, a assimilação dos conteúdos de sentido do AT não só eleva o exercício das práticas sociocristãs para um patamar superior das coisas na fala do Filho, mas sobretudo sugere um intervalo de tempo aberto a essa fala em novas 
situações da vida. Em suma, a (re)leitura da $\mathrm{CH}$ se aplica a tantas outras gerações letradas neste evento, haja vista que o texto se coloca como o discurso dos "últimos dias”.

Outrossim, a escrita da $\mathrm{CH}$ pressupõe fios ideológicos que conectam outros contextos continuados como parte das cadeias comunicativas em atos de leitura e reescrita de sermão em circunstâncias novas que surgem para amplificar práticas letradas nas tradições cristãs.

Finalmente, destacamos neste estudo a importância de entender a fala e a escrita como modalidades complementares, e não dicotômicas, mas sobretudo situadas nos mais diferentes contextos complexos e recorrentes da vida, mesmo quando estamos falando de artefatos escritos como a Carta aos Hebreus.

\section{REFERÊNCIAS}

ADAM, J. M. Textos, tipos e protótipos. São Paulo: Contexto, 2019.

BAKHTIN, M. M. Os gêneros do discurso. São Paulo: Editora 34, 2016.

BAKHTIN, M. M. Para uma filosofia do ato responsável. 2. ed. Pedro \& João, 2012.

BAKHTIN, M. M. Problemas da poética de Dostoiévski. 5. ed. Rio de Janeiro: Forense Universitária, 2015a.

BAKHTIN, M. M. Teoria do romance I: a estilística. São Paulo: Editora 34, 2015b.

BARTON, D. The social nature of writing. In: BARTON, D.; IVANIC, R. (org.). Writing in the Community. London: Sage, 1991.

BAZERMAN, C. Gêneros, agência e escrita. São Paulo: Cortez, 2006.

BAZERMAN, C. Retórica da ação letrada. São Paulo: Parábola Editorial, $2015 a$.

BAZERMAN, C. Teoria da ação letrada. São Paulo: Parábola Editorial, 2015b.

BEAUGRANDE, R. Linguistic theory: the discourse of fundamental works. London; New York: Longman, 1991.

BEAUGRANDE, R. New foundations for a science of text and discourse: cognition, communication, and the freedom of access to knowledge and society. Norwood: Ablex, 1997.

BEZERRA, B. G. Gêneros introdutórios em livros acadêmicos. 2006. Tese (Doutorado em Letras) - Universidade Federal de Pernambuco, Recife, 2006.

BEZERRA, B. G. Gêneros no contexto brasileiro: questões [meta]teóricas e conceituais. São Paulo: Parábola Editorial, 2017. 
BÍBLIA. Português. Almeida Revista e Atualizada. Barueri: SBB, 1993.

EBERT, D. J. Wisdom in New Testament christology, with special reference to Hebrews 1:1-4. Unpublished Ph.D. thesis, Trinity Evangelical Divinity School, 1998.

FAITHLIFE. Software Bíblico Logos. Versão 9.7 SR-19.7.0.0025. Faithlife Copyright. 2021.

FARACO, C. A. Linguagem \& diálogo: as ideias linguísticas do Círculo de Bakhtin. São Paulo: Parábola Editorial, 2009.

GARFINKEL, H. Estudos de etnometodologia. Petrópolis: Vozes, 2018.

GORMAN, M. J. Introdução à exegese bíblica. Rio de Janeiro: Thomas Nelson, 2017.

JAEGER, W. W. Paideia: a formação do homem grego. 6. ed. São Paulo: Editora WMF Martins Fontes, 2013.

JANSON, T. A história das línguas: uma introdução. São Paulo: Parábola, 2015.

KISTEMAKER, S. J. Comentário do Novo Testamento: Exposição de Hebreus. 2. ed. São Paulo: Cultura Cristã, 2013.

KLEIMAN, A. Os significados do letramento: uma nova perspectiva sobre a prática social da escrita. Campinas: Mercado de Letras, 2008.

LANE, W. L. Hebrews 1-8. In: Word Biblical Commentary. Vol. 47a. Dallas, TX: Word, 1991.

LOUW, J. P.; NIDA, E. A. Léxico grego-português do Novo Testamento: baseado em domínios semânticos. Barueri: Sociedade Bíblica do Brasil, 2013.

MARCUSCHI, L. A. Da fala para a escrita: atividades de retextualização. 10. ed. São Paulo: Cortez, 2010.

MARCUSCHI, L. A. Oralidade e escrita. Goiânia, Signótica, v. 9, p. 119-145, 1997.

MARCUSCHI, L. A. Produção textual, análise de gêneros e compreensão. São Paulo: Parábola Editorial, 2008.

MEDVIÉDEV, P. N. O método formal nos estudos literários: introdução crítica a uma poética sociológica. São Paulo: Contexto, 2016.

MILLER, C. R. Gênero textual, agência e tecnologia. São Paulo: Parábola Editorial, 2012.

OLBRICHT, T. H. Hebrews as amplification. In: PORTER, S. E.; OLBRICHT, T. H. (ed.). Rhetoric and the New Testament: Essays from the 1992 Heidelberg Conference. JSNTSS 90. Sheffield: Sheffield Academic Press, 1993. 
SIEGERT, F. Homily and panegyrical sermon. In: PORTER, S. E. (ed.). Handbook of classical rhetoric in the Hellenistic period, 330 B.C.-A.D. 400. Boston; Leiden: Brill Academic Publishers, 2001.

STREET, B. V. Letramentos sociais: abordagens críticas do letramento no desenvolvimento, na etnografia e na educação. São Paulo: Parábola Editorial, 2014.

VAN DIJK, T.A. V. Discurso e contexto: uma abordagem sociocognitiva. São Paulo: Contexto, 2012.

VANHOOZER, K. J. Quadros de uma exposição teológica: cenas de adoração, testemunhos e sabedoria da igreja. Brasília: Monergismo, 2018.

VOLOCHÍNOV, V. N. Marxismo e filosofia da linguagem. São Paulo: Editora 34, 2017.

WALLACE, D. B. Gramática grega: uma sintaxe exegética do Novo Testamento. São Paulo: Editora Batista Regular, 2009.

WALTON, J. H.; SANDY, D. B. The lost world of scripture: ancient literary culture and biblical authority. Downers Grove: IVP Academic, 2013.

Recebido para publicação em: 1 jun. 2021. Aceito para publicação em: 29 set. 2021. 